\title{
Sintesis dan Analisis Spektra IR, Difraktogram XRD, SEM pada Material Katalis Berbahan Ni/zeolit Alam Teraktivasi dengan Metode Impregnasi
}

\author{
Nur Fitri Fatimah dan Budi Utami \\ Program Studi Pendidikan Kimia FKIP \\ Universitas Sebelas Maret \\ nurfitri975@gmail.com
}

\begin{abstract}
Abstrak
Dalam penelitian ini dilakukan penelitian tentang sintesis dan analisis spektra IR, difraktogram XRD, SEM pada material katalis berbahan Ni/zeolit alam teraktivasi dengan metode impregnasi. Tujuan penelitian ini untuk mengetahui: (1) sintesis katalis Ni/zeolit dengan metode impregnasi, (2) karakteristik katalis Ni/zeolit menggunakan FT-IR, XRD, dan SEM, dan (3) perbandingan optimum Ni dan zeolit dalam sintesis katalis $\mathrm{Ni}$ /zeolit.

Penelitian ini dilakukan menggunakan metode eksperimen laboratoris. Sintesis katalis Ni/zeolit dibuat melalui pencampuran larutan $\mathrm{Ni}\left(\mathrm{NO}_{3}\right)_{2} \cdot 6 \mathrm{H}_{2} \mathrm{O}$ dengan zeolit alam teraktivasi asam. Proses pencampuran dilakukan dengan variasi $\mathrm{Ni}$ yang terimpregnasi dalam zeolit alam teraktivasi sebanyak $0 \%, 5 \%$, dan $10 \%$. Identifikasi gugus fungsi hasil sintesis katalis Ni/zeolit ditentukan dengan FT-IR, identifikasi derajat kristalinitas $\mathrm{Ni}$ /zeolit ditentukan dengan XRD dan struktur morfologi katalis Ni/zeolit menggunakan mikrografi SEM.

Berdasarkan penelitian yang telah dilakukan, dapat disimpulkan bahwa: (1) katalis Ni/zeolit dapat disintesis dari larutan $\mathrm{Ni}\left(\mathrm{NO}_{3}\right)_{2} \cdot 6 \mathrm{H}_{2} \mathrm{O}$ dengan variasi jumlah $\mathrm{Ni}$ yaitu $0 \%$, 5\%, dan $10 \%$ dengan metode impregnasi, (2) karakteristik katalis $\mathrm{Ni} / z e o l i t$ dapat diketahui dari analisis kristalinitas puncak-puncak zeolit dan Ni dalam difraktogram XRD, struktur morfologi SEM, serta analisis perubahan bentuk spektrum gugus fungi dengan menggunakan FT-IR, zeolit alam dengan logam Ni untuk menghasilkan katalis Ni/zeolit dengan perbandingan optimum adalah pada variasi $\mathrm{Ni} 5 \%$. Hal ini didukung dengan hasil karakterisasi menggunakan SEM (Scanning Electron Microscope) yang menggambarkan morfologi permukaan katalis Ni/zeolit.
\end{abstract}

Kata-kata kunci: sintesis, material katalis, zeolit, impregnasi

\begin{abstract}
This research is about the synthesis and analysis of IR spectra, XRD difractogram, SEM in the catalyst material made from Ni/zeolite nature is activated by impregnation method. This study is aimed to find out (1) The method of synthesis of catalyst Ni/zeolit with impregnation (2) The characteristics of the catalyst which is formed from the characterization results using SEM, FT-IR, and XRD (3) the optimum ratio of zeolit and Ni in the synthesis of catalyst Ni/zeolit.

Synthesis of catalyst Ni/zeolit were done by impregnation. Method with a variety of Ni concentration range $0 \%, 5 \%$, and 10\%. Characterization of catalyst Ni/zeolit were produced covering the structure morphology and particle size using microgrpahy SEM (Scanning Electron Microscope). While characterization crystallization and the crystal size was performed using diffractogram of XRD (X-Ray Diffraction) and characterization with FT-IR.

From this study it can be concluded that : (1) Ni/zeolit catalyst be synthesized from a solution of $\mathrm{Ni}\left(\mathrm{NO}_{3}\right)_{2} \cdot 6 \mathrm{H}_{2} \mathrm{O}$ at variance $0 \%, 5 \%$, and $10 \%$ with impregnation method, (2) characteristics of $\mathrm{Ni} / z e o l i t$ catalyst were identified using SEM analysis in the form of uneven surface morphology, the XRD, the peaks of $\mathrm{Ni} z$ eolit cryztallinity and FT-IR, (3) Comparison of optimum mixing from Ni and zeolit in the synthesis og $\mathrm{Ni} / z e o l i t$ catalyst on the results of analysis using XRD, SEM, and FT-IR is the Ni variance of $5 \%$.
\end{abstract}

Keywords: synthesis, catalyst, zeolit, impregnation

\section{PENDAHULUAN}

Katalis banyak digunakan dalam proses industri seperti dalam proses produksi bahan kimia, proses produksi makanan, pembangkit listrik tenaga nuklir, kendaraan, dan pengendalian pencemaran. Katalis harus mempunyai kriteria sifat-sifat umum dalam penggunaan seperti sifat aktif, stabil, sensitif 
terhadap perubahan panas, mudah diregenerasi dan mempunyai kekuatan mekanik. Logam transisi (golongan B) dapat berfungsi sebagai katalis. Cara Mudah untuk mendapatkan katalis yang mempunyai luas permukaan komponen aktif yang luas dan mudah dalam pemakaiannya yaitu adalah dengan mendispersikan komponen aktif pada pengemban (Handoko, 2009; Huheey, 1978; \& Triyono, 2010).

Penelitian ini mencoba menggunakan katalis heterogen yaitu zeolit alam yang diaktivasi sehingga akan memudahkan separasi katalis dari produk. Seperti diketahui zeolit mempunyai struktur berongga dan biasanya rongga ini diisi oleh air dan kation yang bisa dipertukarkan dan memiliki ukuran pori yang tertentu. Oleh karena itu, zeolit dapat dimanfaatkan sebagai penyaring, penukar ion, adsorben dan katalis.

Pengembanan komponen aktif katalis pada suatu pengemban dapat meningkatkan selektifitas katalis (Oudejans, 1984 \& Satterfield, 1980). Pengembanan campuran logam ke bahan pendukung untuk menghasilkan katalis bimetal dapat dilakukan dengan berbagai metode, salah satunya dengan metode impregnasi.

Pengembanan logam Ni yang terlalu banyak memungkinkan terjadinya penggumpalan sehingga akan terbentuk agregat begitu pula sebaliknya jika logam Ni yang diembankan terlalu sedikit maka logam Ni tidak akan mencukupi untuk menempel pada zeolit, sehingga letak antar logam Ni menjadi sangat jarang. Terbentuknya agregat dan distribusi logam yang tidak merata tentunya akan mempengaruhi jumlah situs aktif dari katalis yang terbentuk sehingga akan berpengaruh pada produk. Trisunaryanti, dkk. (2005) melaporkan bahwa semakin banyak jumlah logam Ni dalam katalis Ni$\mathrm{Mo} / z e o l i t$ akan menyebabkan penurunan keasaman, meskipun masih lebih tinggi daripada keasaman zeolit alam sebelum penambahan Ni. Oleh karena itu, adanya variasi kadar $\mathrm{Ni}$ bertujuan untuk mengetahui jumlah $\mathrm{Ni}$ pada zeolit yang dapat memberikan karakter dan aktivitas terbaik.

Berdasarkan uraian di atas, maka penelitian yang mengarah pada pembuatan material katalis berbahan $\mathrm{Ni} / \mathrm{ZA}$ dengan variasi kadar logam dan dilakukan penelitian mengenai analisis Spektra IR, SEM dan Difraktogram XRD pada katalis Ni/zeolit untuk mendapatkan kondisi optimum dari vaiasi katalis $\mathrm{Ni} /$ zeolit dengan harapan dapat memberikan manfaat yang lebih kepada masyarakat.

\section{METODE}

\section{Preparasi Zeolit}

Proses modifikasi dimulai dengan perendaman zeolit alam yang didapat dari Klaten bentuk butiran direndam dalam akuades sambil diaduk dengan pengaduk besi selama satu jam pada temperatur kamar. Disaring dan endapan yang bersih dikeringkan dalam oven pada temperatur $100^{\circ} \mathrm{C}$ selama 3 jam, kemudian dihaluskan dengan cara digerus lalu disaring dengan saringan lolos 70 mesh, selanjutnya dikalsinasi pada temperatur $500^{\circ} \mathrm{C}$ selama 4 jam.

\section{Aktivasi dan Karakterisasi Zeolit}

Prosedur Aktivasi Zeolit yang pertama adalah mencampurkan zeolit alam 40 gram ke dalam 800 $\mathrm{ml} \mathrm{HCl} 4 \mathrm{M}$, campuran tersebut ke dalam labu leher tiga yang telah dilengkapi refluks pendingin dan magnetic stirrer, memanaskannya dengan air dalam waterbath hingga suhu $90^{\circ} \mathrm{C}$. Waktu pengadukan selama 5 jam, dihitung setelah suhu larutan tercapai. Selanjutnya zat disaring dan dicuci dengan menggunakan aquades hingga netral. Katalis yang terbentuk dikeringkan dalam oven pada suhu $110^{\circ} \mathrm{C}$, Selanjutnya katalis tersebut dikalsinasi pada suhu $550^{\circ} \mathrm{C}$ selama $5 \mathrm{jam}$.

Katalis zeolit diaktivasi dengan jalan direfluk menggunakan $\mathrm{HCl} 4 \mathrm{M}$ selama 5 jam pada temperatur $90^{\circ} \mathrm{C}$ sambil diaduk dengan pengaduk magnet. Proses refluk dilakukan sebanyak 4 kali dengan massa tiap satu kali refluk adalah 25 gram zeolit dan $500 \mathrm{ml} \mathrm{HCl} 4 \mathrm{M}$. Setelah itu dilanjutkan dengan penyaringan dan pencucian dengan akuades sampai $\mathrm{pH}=6$. Kemudian dikeringkan dengan oven pada temperatur $110^{\circ} \mathrm{C}$ selama 5 jam. Dari penelitian tersebut diperoleh 50 gram zeolit yang teraktivasi asam. Perbedaan zeolit awal dengan yang sudah diaktivasi adalah zeolit yang telah teraktivasi warnanya putih bersih dan sangat halus. Zeolit teraktifasi dikarakterisasi menggunakan XRD, SEM, dan FT-IR.

\section{Pembuatan Katalis Ni/Zeolit}

Untuk tahap prosedur impregnasi zeolit dengan $\mathrm{Ni}$ adalah sebagai berikut membuat suspensi zeolit yang telah diaktivasi dengan menambahkan aquades, kemudian membuat larutan $\mathrm{Ni}\left(\mathrm{NO}_{3}\right) \cdot 6 \mathrm{H}_{2} \mathrm{O}$ dan mengimpregnasi larutan $\mathrm{Ni}\left(\mathrm{NO}_{3}\right) \cdot 6 \mathrm{H}_{2} \mathrm{O}$ ke suspensi zeolit pada suhu $70-80^{\circ} \mathrm{C}$, dilakukan pengadukan selama 3 jam dengan magnetic stirer sampai katalis berbentuk pasta. Kemudian. dioven pada suhu $110^{\circ} \mathrm{C}$ Mengkalsinasi katalis pada suhu $350^{\circ} \mathrm{C}$ selama 3 jam. Zeolit terimpregnasi dikarakterisasi menggunakan XRD, SEM, dan FT-IR. 


\section{HASIL DAN PEMBAHASAN}

Zeolit alam diaktivasi dengan cara diasamkan menggunakan asam mineral $\mathrm{HCl}$ untuk menghilangkan senyawa anorganik yang menutup pori-pori pada zeolit serta mengurangi jumlah kation dalam zeolit. Pada proses aktivasi, ion $\mathrm{H}^{+}$akan bereaksi mengurai ikatan atom $\mathrm{Al}$ yang berada pada struktur zeolit. Ion $\mathrm{H}^{+}$ini akan menyerang atom oksigen yang terikat pada $\mathrm{Si}$ dan Al. Berdasarkan harga energi dissosiasi ikatan Al-O (116 kkalmol $\left.{ }^{-1}\right)$ jauh lebih rendah dibandingkan energi disosiasi ikatan Si-O (190 kkalmol $\left.{ }^{-1}\right)$, maka ikatan Al-O jauh lebih mudah terurai jika dibandingkan dengan Si-O, sehingga ion $\mathrm{H}^{+}$akan cenderung menyebabkan terjadinya pemutusan ikatan Al-O dan akan membentuk terbentuk gugus silanol.

Zeolit teraktivasi asam memiliki nilai keasaman paling rendah hal ini dapat terjadi karena zeolit alam terkativasi asam memiliki pengotor yang lebih banyak dari pada yang telah di sintesis menggunakan $\mathrm{Ni}$. Pengaruh adanya $\mathrm{Ni}$ juga meningkatkan kemampuan zeolit untuk mengikat $\mathrm{H}$ pada $\mathrm{NH}_{3}$. Secara sederhana reaksi yang terjadi sesuai Gambar 3.

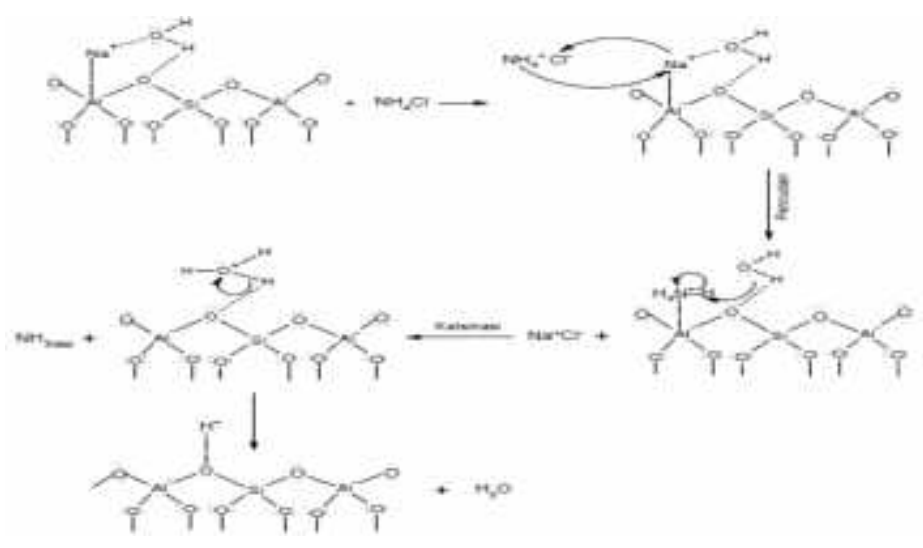

Gambar 1. Proses Aktivasi pada Katalis
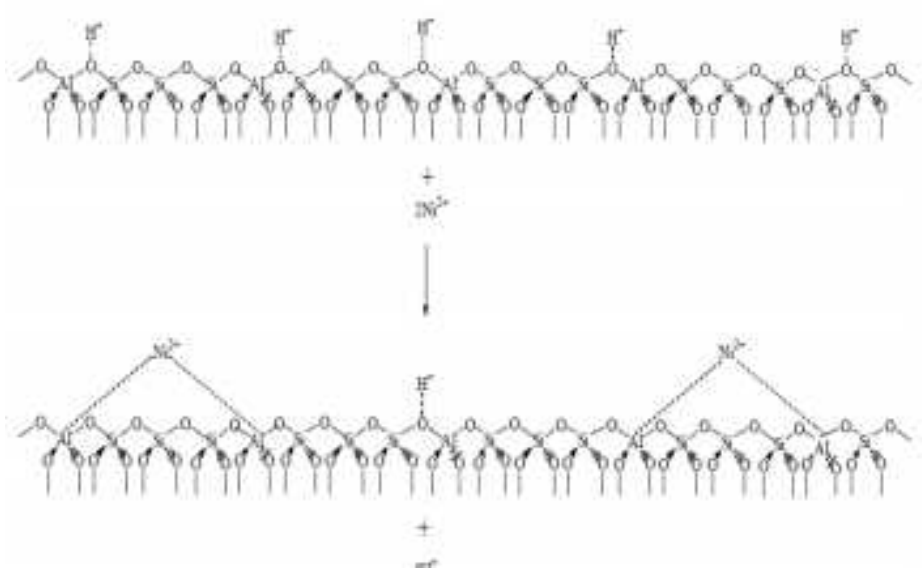

Gambar 3. Proses Impregnasi Ni pada Zeolit

\section{Karakterisasi Katalis Ni/zeolit}

Analisa Difraksi sinar $\mathrm{X}$ atau $X$-ray diffraction (XRD) adalah suatu metode analisa yang digunakan untuk mengidentifikasi fasa kristalin dalam material dengan cara menentukan parameter struktur kisi serta untuk mendapatkan ukuran partikel. Profil XRD juga dapat memberikan data kualitatif dan semi kuantitatif pada padatan atau sampel. Penempatan komponen aktif logam Ni ke dalam sistem pori pengemban bertujuan untuk memperbanyak jumlah situs aktif (active site). Harapannya adalah pada saat proses konversi, kontak antara reaktan dengan katalis semakin besar, sehingga reaksi akan berjalan dengan cepat dan produk cepat terbentuk. Proses impregnasi terjadi pertukaran kation antara kation dalam Natural Zeolit Acid (NZA) dan sisa logam dengan kation $\mathrm{Ni}^{2+}$ yang diimpregnasikan. Banyaknya $\mathrm{Ni}^{2+}$ yang terimpregnasi sangat dipengaruhi oleh sifat alami kation $\mathrm{Ni}^{2+}$ yang diimpregnasikan. Namun, selain dipengaruhi oleh sifat alami kation yang diimpregnasikan, faktor lain yang dapat mempengaruhi proses impregnasi berasal dari jenis kerangka kerja dan ketidak murnian NZA sebagai matriks pengemban.

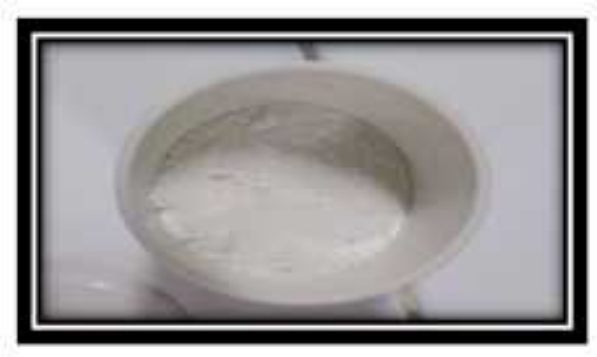

Gambar 2. Hasil Aktivasi Zeolit
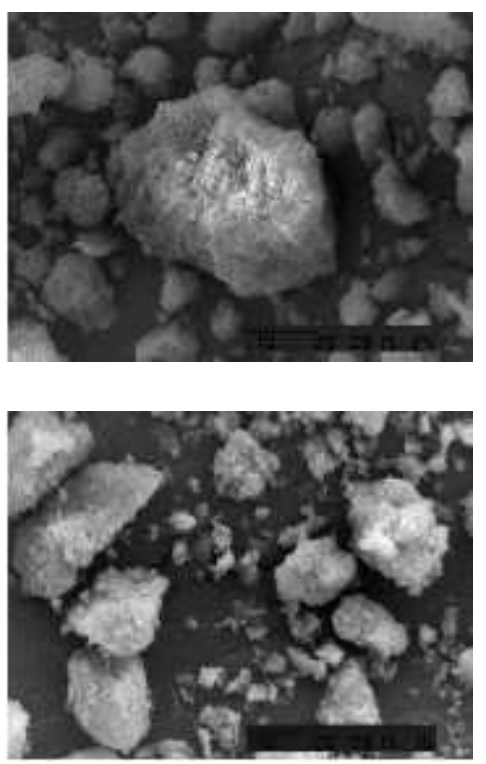

Gambar 6. Hasil SEM (a) Zeolit teraktivasi asam (b) Zeolit teraktivasi asam hasil impregnasi dengan $\mathrm{Ni}$ 


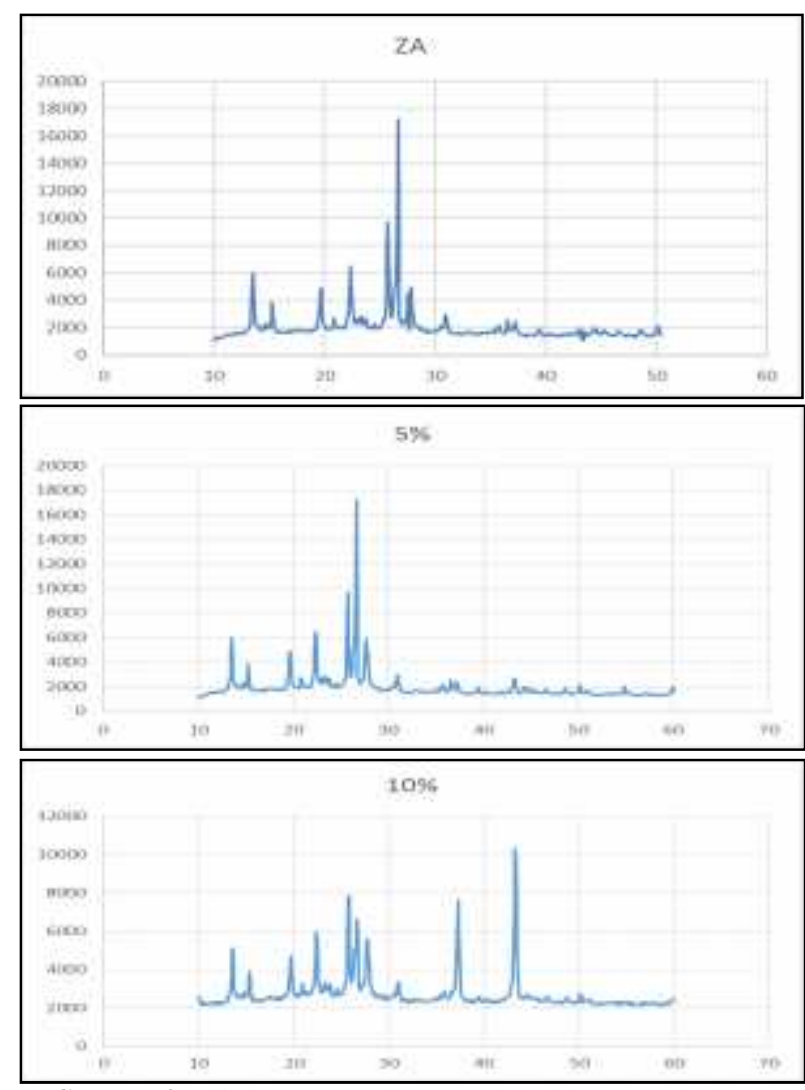

Gambar 4. Difraktogram zeolit yang telah di impregnasi Ni (a)

Zeolit Alam (b) Ni/zeolit Alam 5\% (c) Ni/zeolit $10 \%$

Dari hasil XRD menjelaskan bahwa Ni telah berhasil diimpregnasi ke dalam zeolit alam teraktivasi. Kemurnian zeolit ditunjukan dengan adanya serapan pada nilai $2 \theta$ sebagai berikut: 19,65150; 22,2520; 25,65250; dan 27,75280. Hasil difraktogram katalis $\mathrm{Ni}$ /zeolit mirip dengan difraktogram zeolit alam menunjukkan proses sintesis yang dilakukan telah berhasil disintesis

dengan adanya serapan pada $2 \theta \quad 46,55420$ menunjukan adanya logam dan $\mathrm{Ni}$ hasil impregnasi pada zeolit.

Hasil FT-IR impregnasi Ni menunjukan pada panjang gelombang $1383,98 \mathrm{~cm}^{-1}$ mempunyai pita lemah dibandingkan dengan hasil FT-IR zeolit sebelum diimpregnasi, sehingga dapat disimpulkan bahwa zeolit telah terimpregnasi dengan kualitas terbaik ada pada penambahan Ni 5\%. Gambar 6 a dan b menunjukan keadaan morfologi dasar dari zeolit yang digunakan sebagai katalis dari gambar yang ada dapat di simpulkan bahwa zeolit yang telah disintesis.

\section{KESIMPULAN}

Dari penelitian yang telah dilakukan dapat disimpulkan beberapa hal dari data yang di hasilkan yaitu : 1) Katalis Ni/zeolit dapat disintesis dari zeolit alam dan larutan $\mathrm{Ni}\left(\mathrm{NO}_{3}\right)_{2} \cdot 6 \mathrm{H}_{2} \mathrm{O}$ dengan varian $\mathrm{Ni}$
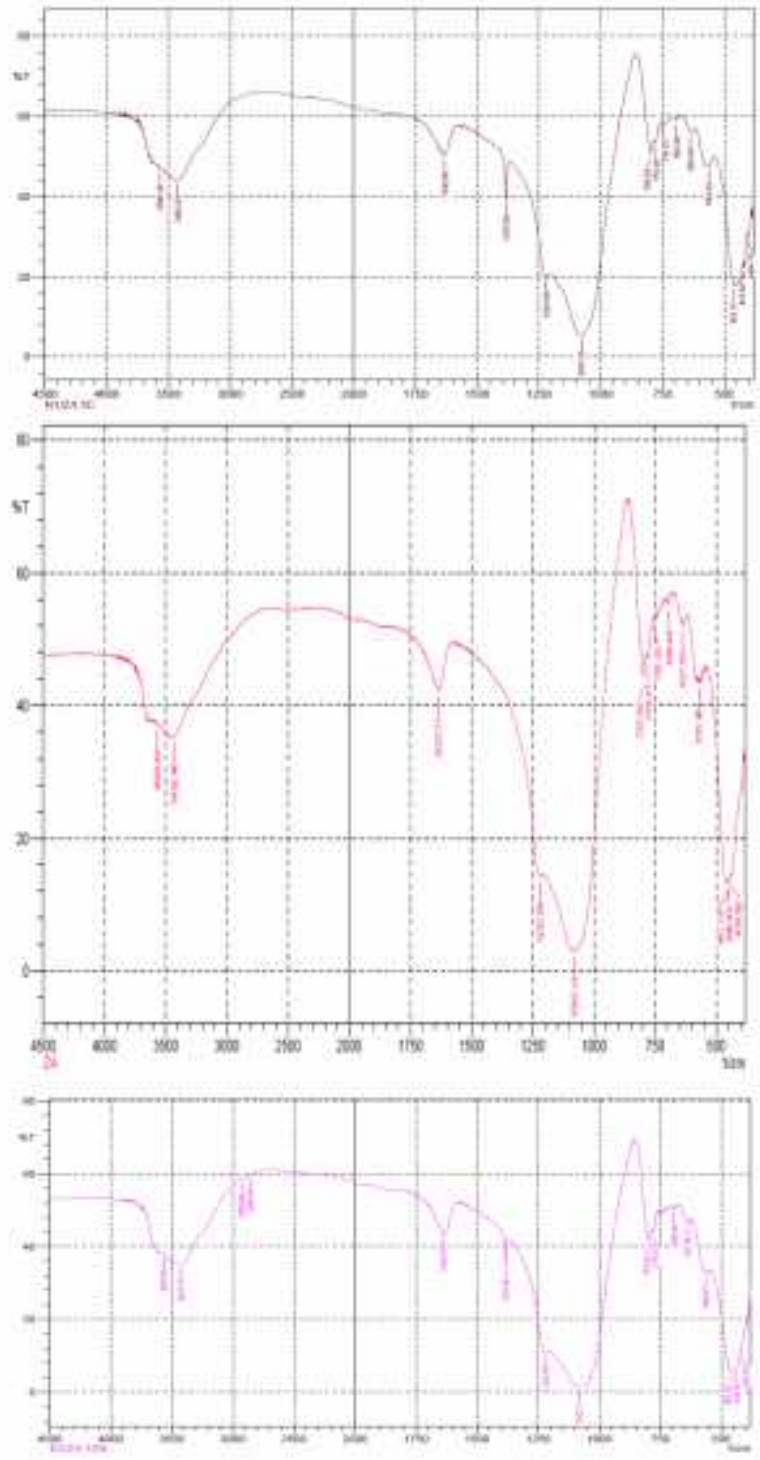

Gambar 5. Analisis Spektra IR

$0 \%$, 5\%, dan $10 \%$ selanjutnya disintesis dengan menggunakan metode impregnasi sambil diaduk dengan magnetic stirrer sehingga terbentuk seperti pasta, 2) Karakteristik katalis Ni/zeolit dapat diketahui dari analisis kristalinitas puncak puncak zeolit dan Ni dalam difraktogram XRD, struktur morfologi SEM, serta analisis perubahan bentuk spektrum gugus fungsi dengan menggunakan FTIR. Zeolit alam disintesis dengan logam $\mathrm{Ni}$ untuk menghasilkan katalis Ni/zeolit dengan perbandingan optimum adalah pada variasi $\mathrm{Ni} 5 \%$. Hal ini didukung dengan hasil karakterisasi menggunakan SEM (Scanning Electron Microscope) yang menggambarkan morfologi permukaan katalis $\mathrm{Ni} /$ zeolit. Disamping itu, juga didukung dengan analisa karakterisasi mengggunakan XRD (X-Ray Diffraction) yang menunjukkan puncak-puncak dengan tajam dan gugus fungsi dengan FTIR. 


\section{DAFTAR PUSTAKA}

Handoko, D.S.P. 2009. Aktivitas Katalis Ni/zeolit Pada Konversi Katalitik Metil Ester Minyak Goreng Jelantah (MEWCO) Pada Temperatur $450^{\circ} \mathrm{C}$ menjadi Senyawa Fraksi Bahan Bakar. Jurnal Ilmu Dasar, 8(1): 1-13.

Huheey, J.E. 1978. Inorganic Chemistry. Principles of Structure and Reactivty Second Edition. New York: Harper Inc.

Oudejans, J.C. 1984. Zeolit Catalyst in Some Organic Reaction. Holland: The Netherland Foundations for Chemical Research.
Satterfield, C.N. 1980. Heterogenous Catalyst In Practice. Mc Graw Hill Book Company. New York.

Trisunaryanti, W., Triwahyuni, E., \& Sudiono,S. 2005. Preparasi, Modifikasi Dan Karakterisasi Katalis Ni-Mo/Zeolit Alam Dan Mo-Ni/zeolit Alam. TEKNOIN, 10(4), 269-282.

Triyono. 2010. Kimia Katalis. Yogyakarta: Jurusan Kimia Fakultas Matematika dan Ilmu Pengetahuan Alam Universitas Gadja Mada: 101. 